\title{
Cross-cultural Comparison of Gratitude Expressions in Persian, Chinese and American English
}

\author{
Reza Pishghadam (Corresponding author) \\ English Department, Ferdowsi University of Mashhad \\ PO box 91779-48974, Park Square, Ferdowsi University Mashhad, Iran \\ E-mail: rpishghadam@yahoo.com \\ Sima Zarei \\ English Department, Ferdowsi University of Mashhad \\ PO box 91779-48974, Park Square, Ferdowsi University Mashhad, Iran \\ E-mail: sima.zarei@yahoo.com
}

Received: August 10, 2011

Accepted: August 22, 2011

Published: January 1, 2012

doi:10.5539/elt.v5n1p117

URL: http://dx.doi.org/10.5539/elt.v5n1p117

\begin{abstract}
Granted the fact that different cultures have different speaking styles, knowledge of these styles can help people grasp the essence of social cultural knowledge to communicate with others more successfully. In this regard, the present paper aims at comparing the use of speech act of gratitude in Persian and Chinese EFL learners and English native speakers performances to identify the existing pattern among them. For this purpose, the participants were asked to complete a Discourse Completion Task (DCT) designed by Eisenstein and Bodman (1993). The results revealed that although thanking is regarded as the most favorite strategy among all three groups, there are significant differences in the ways Persian and Chinese learners of English, and also native speakers of English use the speech act of thanking.
\end{abstract}

Keywords: Culture, Pragmatic Competence, Speech act, Speech act of gratitude

\section{Introduction}

Language plays an important role in culture. Every language has cultural concepts and contextual usages in a way that its native speakers form similar conceptions about the world. Many studies on cultural differences revealed that people with different cultures have different speaking styles. The differences of speaking styles are signs of the differences in cultural value, so people can communicate with others successfully at the time they grasp the essence of social cultural knowledge (Wang, 2011; Tian, 2010 among them).Miscommunications are often the result of cross-cultural discourse differences (Bardovi-Harlig \& Dörnyei, 1998) since the pragmatic competence of native speakers and L2 learners may be different (Cohen, 1996).

Generally, study on cultures is divided into two kinds of cross-cultural and inter-language pragmatic (ILP) studies. Cross-cultural interaction is defined as the face-to-face interaction between people from different cultural backgrounds including empirical studies that investigates various speech acts (e.g. Wolfson, 1981), whereas ILP concentrates on the influence of pedagogical issues on pragmatic development (e.g. Ghobadi \& Fahim, 2009). ILP studies show how nonnative speakers perceive and produce actions in a target language, and it investigates how L2 learners develop the ability to understand and perform action in a target language (Kasper \& Rose, 2002). In order to develop communicative competence, doing some communicative tasks with communicative purpose will help learners to acquire the norms of second culture which vary across cultures (Blum-Kulka, 1982; Rose \& Kasper, 2001). The lack of pragmatic competence will result in pragmatic failure and communication breakdown (Blum-Kulka \& Olshtain, 1986).

Intercultural competence is the ability to interact effectively and appropriately with those who are linguistically and culturally different (Intachakra, 2004). Intercultural communication creates awareness about the importance of understanding speech acts cross-culturally. The recognition of the meaning of a particular speech act in a given cultural setting is at the heart of successful intercultural communication (Lee, 2005; \& Al-Khateeb, 2009). If 
learners lack the necessary knowledge and experience in using sociocultural norms of second language, they will have difficulties in interactions due to not having an appropriate understanding of 12 grammar rules (Amaya, 2008). Brown (2001) claimed that successful mastery of the second language will be the result of the learner's own personal investment of time, efforts, and attention to the target language.

One of the aspects of pragmatics which is widely examined includes the production and comprehension of speech acts which are the utterances that speakers employ for different functions such as requesting, apologizing, suggesting, etc (Olshtain \& Cohen, 1991). The logic behind studying speech acts is that language learners need to use different speech acts which set for the purpose of communicating in an appropriate manner with native speakers. Speech act is the performance of certain act through words. Cohen (1996) claimed that not only the linguistic realization of the same speech act differs, but also the force of speech act might differ. Thus this study attempts to investigate the similarities and differences in speech act of gratitude to help learners develop their pragmatic competence.

In fact, this study attempts to explore how Persian and Chinese EFL learners realize gratitude speech act and whether their gratitude strategies map those of native speakers.

\section{Theoretical Background}

Although the study of speech act has a rather long history (began in 1960), the study of production and perception of speech act has been investigated for last 15 years. So far, there are lots of studies carried out on speech acts realization. Plenty of them are cross-cultural studies which compared and contrasted English speech acts with other languages.

Expressions of gratitude as a speech act in comparison to other speech acts drew less attention in our daily conversations. This speech act has been analyzed by Austin (1962), Searle (1976), and Brown and Levinson (1987). Austin (1962) placed Speech act of gratitude in the class of behabitative, which are concerned with our attitudes and expressions of attitudes toward one's social behavior. Searle (1976) on the other hand, includes expressions of gratitude into the class of expressives, since the speaker expresses his/her gratitude for a past act done by the hearer. Brown and Levinson (1987) categorized thanking as face threatening act in which the speaker feels indebted to the hearer. Contrary to what Brown and Levinson (1987) mentioned, Intachakra (2004) stated that expressions of gratitude will satisfy both party's face if applied properly, whereas failing to use it correctly may result in rudeness and impoliteness.

Major works on the speech act of gratitude is done by Eisenstain and Bodman $(1993,1986)$ who analyzed the responses of receiving a gift, favor, reward or service, and rated the responses for appropriateness on the basis of native speakers' performance on thanking and as a result developed a code system. On their first study in 1986 observed that the language function of expressing gratitude is used frequently among friends, strangers, superiors, and subordinates. If it is performed successfully, it can provide feeling of warmth and solidarity. They examined native and nonnative speakers of American English (Chinese, Korean, Spanish, Japanese and Russian) in expressing gratitude using ethnographic methods, observation of naturally occurring interactions, and also taking field notes. They provided 15 situations in their questionnaire and then interviewed speakers. They stated that foreign language learners are unaware of underlying rules of expressing gratitude, assuming that these expressions are universal; and therefore, ignore the differences in the realization of this speech act between cultures. They indicated in their study that in expressing gratitude both positive and negative feelings are present on the part of giver and receiver.

Later, they conducted a study in 1993 and did four experiments (using integrating written, oral questionnaire, role playing, and naturally observation). The findings of the study showed that thanking as a speech act developed mutually; "the giver and the thanker collaborate in the development of a successful thanking episode" (p. 74). The differences were obvious in both pragmalinguistics and sociopragmatics level; that is, they involved both kinds of events and the extent speakers are familiar with the context. Their results also showed that even advanced learners had difficulty in expressing gratitude, so they needed information on the nature of what to say, the language used to express it, and the context in which it was needed.

In another study, Creese (1991) studied the similarities and differences between American and British speakers in five speech acts of requesting, apologizing, greeting, complimenting, and thanking. He found that compliments are used to show gratitude and solidarity. The results of his study also showed that British people use more full form of thank you rather than the word thanks.

In a similar vein, Al-Khateeb (2009) explored the speech act of thanking as a compliment response by Arab learners of English adopting Discourse Completion Test (DCT) to investigate the differences in realizing this speech act between Arab and English cultures (the influence of speaker's culture on the pragmatic performance) and to see the influence of 
gender and proficiency on the use of this speech act. The findings of the study revealed that Arab speakers are not able to produce target like responses due to negative pragmatic transfer. They tend to generalize their first language strategies and expression to second language situations. This testifies to the fact that they only acquire the linguistic competence in classroom, and the pragmatic competence is ignored. They simply translate the utterances regardless of the illocutionary force associated to them in second language. Most of the utterances used by Arabs are lengthier indicating that the Arabs are more sincere in their thanking. The proficiency and gender did not play a significant role in producing target like responses.

Farina and Suleiman (2009) did a pilot study and examined the speech act of gratitude among Iranian English as Foreign Language (EFL) learners through handling a written DCT to ten people. Iranian respondents of this study used more thanking strategies in comparison with their American counterparts. The findings of this study suggested that language proficiency did not affect EFL learners' use of strategies when expressing gratitude in the English language.

Jung (1994) examined the expressions of gratitude and responses in American English through observation. He further noted that selection of gratitude expression depends to some extent on the evaluation of the speaker of the favor done and on expressions of gratitude functions.

Rubin (1983) as cited in Eisenstain and Bodman (1986) investigated the way people express their gratitude in different situations. He introduced more functions besides expressions of gratitude as closing the conversation or compliment. She also called automatic type of thanking in service encounters 'bald' and mentioned that if speakers felt that the hearer has taken up his time, money or efforts for him, he will express his gratitude more elaborately.

Cheng (2005) examined expressions of gratitude utilized by English learners in China considering pragmatic development. He stated the pattern of strategy use by both Chinese English learners and Americans, concluding that both have the same preference in the usage of strategies in general; however, Chinese learners differed in the use of terms of address interacting high and low status. American speakers use more thanking, appreciate, and repayment strategies than Chinese English learners. Furthermore, he found that social status and imposition were two factors influencing number of strategy use. Chang (2008) in the same line compared Chinese English learners and English speakers' perception and production of expressions of gratitude utilizing DCT. He noticed the same preference between the two groups in expressing gratitude and number of strategies. Social status, size of imposition, and language proficiency influenced the reactions of the speakers. Concerning imposition, the speakers were more indebted if they felt they could cause more imposition to the hearer.

\section{Purpose of the Study}

The objective of the study is to compare the use of speech act of gratitude in Persian and Chinese EFL learners, and also English native speakers' performances to identify the existing pattern among them. So the research questions would be as follows:

1. What are the common gratitude strategies used by Persian EFL learners?

2. What are the common gratitude strategies used by Chinese EFL learners?

3. What are the common gratitude strategies used by English native speakers?

4. How do Chinese and Persian EFL learners and English native speakers differ in their use of expressions of gratitude?

\section{Methodology}

\subsection{Participants and Setting}

The total population participating in this study consisted of 180 individuals who were all native speakers of Persian. They were students whose age ranged from 22 to 26, and were studying English as a foreign language in Mashhad (a city in Iran) in Ferdowsi University and private language institutes. There were 35 Chinese speakers taking part in the study who were learning English as a second language; all of them were in their twenties. They had completed their bachelor's degrees and all were working as sales managers of different companies in China. And finally, 35 English participants studied by Cheng (2005) were regarded as the baseline data. They were graduate students whose age ranged from 22 to 41 and studied science and humanities at the University of Iowa in China.

\subsection{Instrumentation}

In order to address the research questions, the participants were asked to complete a DCT designed by Eisenstein and Bodman (1993), which took 20 minutes to answer the questions. The reason for using this method is that through discourse completion questionnaires one will gather a lot of data at a time (Cohen, 1996). The content validity of this questionnaire was substantiated through a pilot study done on 10 students. Based on the 
recommendations and feedback received from the participants, questions were revised and taken into consideration for forming the final DCT (see Appendix). Finally, the scenarios in the DCT were modified and adapted to the Iranian context of English learning. The DCT was administered to the participants who responded to 14 situations which required them to feel, to different degree, obliged or grateful to someone who has done something for them or requested a favor. The participants were supposed to imagine themselves in each situation and respond accordingly based on their immediate reaction. Moreover, to reach a sound reliable data, two raters corrected the respondents' replies.

\subsection{Procedure}

The data were collected by means of the DCT open-ended questionnaire to get more information from the participants. The participants pictured themselves in the situations and responded accordingly. They wrote down as many words or utterances as they wanted to express their gratitude towards the speaker.

For analyzing the data, the first step was to identify the gratitude strategies in the provided utterances. Since the study is concerned with expressions of gratitude, the coding system devised by Cheng (2005) was adopted. It is based on 8 strategies for expression of gratitude:

1) Thanking

A. simple thanking by only using the word "thank you"

B. thanking by stating the favor (thank you for your help, and thank you for your notice exemplify this sub-strategy)

C. thanking and mentioning the imposition caused by the favor (Thank you for helping me cleaning the room)

2) Appreciation

A. using the word "appreciate" (e.g. I appreciate it!)

B. using the word "appreciate" and mentioning the imposition caused by the favor (e.g. I appreciate the time you spent for me)

3) Repayment

A. offering services, food... (next time is my turn)

B. feeling indebted (I owe you one)

C. promising future self-improvement (it won't happen again)

4) Recognition of imposition

A. by acknowledging the imposition (exemplified by statements such as I know you are not allowed to give me extra time)

B. stating or diminishing the need for the favor (you shouldn't do that)

5) Apology

A using the apologizer words (I am sorry)

B. using apology by stating the favor (I am sorry for the problem I made)

C. expressing embarrassment (I feel embarrassed)

D. criticizing oneself (I am such a fool...)

6) Positive feeling

A. expressing positive reaction to a person (You are a life saver)

B. expressing positive feeling to action (such as This book was really helpful)

7) Other

Expressions that do not belong to the mentioned strategies are categorized as other strategies comprising

A. here statements (here you are)

B. small talk

C. leave taking (good bye, have a nice day)

D. Joking

8) Alerter by using titles and names, attention getter in addition to the other strategies forms the alerter strategy. 
The categorization was approved by two other experts in the field. With regard to data analysis, all data were transcribed and coded according the classification scheme proposed by Cheng (2005). The data were analyzed quantitatively. For the analysis, frequency counts of the semantic formulas used in the realization of the speech act of gratitude was calculated and compared across the fourteen thanking situations.

\section{Results}

Statistical calculations are shown in the following tables representing the eight categories of gratitude strategies Persian and Chinese EFL learners, and also English native speakers tend to use.

Table 1 shows the percentages and frequencies of the strategies used by Persian, English, and Chinese speakers of English. Thanking strategy is the most regular one. Half of the strategies Chinese EFL learners used were related to thanking $(\mathrm{p}=48 \%$ ). $43 \%$ of the strategies of Persian EFL learners' responses and $35 \%$ of English native speakers were attributed to the same strategy. As Table 1 report, $12 \%$ of English native speakers were classified under the category of appreciation. 5\% of Chinese and 3\% of Persian EFL learners' responses were attributed to appreciation. Concerning the third strategy in the gratitude classification, Chinese EFL learners and English native speakers shared approximately the same percentage expressing their positive feeling either to hearer or action, while Persian EFL learners preferred to convey their positive feeling more than the other two groups. The findings illustrated that all three groups indicated the same inclination in choosing repayment strategy.

Table 1 also exhibits that English native speakers and Chinese EFL learners used apology equally in their responses $(p=7 \%)$. Examining the imposition strategy, $6 \%$ of the whole were related to English native speakers, $2 \%$ to Chinese and $1 \%$ to Persian EFL learners. As for the alerter strategy, Persian and Chinese EFL learners and English native speaker used this strategy similarly. Finally, all three groups tend to employ the other strategy in a similar way.

The summary of the results obtained is shown below:

Persian EFL learners: Thanking $>$ positive feeling $>$ Repayment $=$ Alerter $>$ Appreciate $=$ Apology $=$ Other $>$ Imposition

Chinese EFL learners: Thanking $>$ Alerter $>$ Repayment positive feeling $>$ Apology $>$ Appreciate $>$ Imposition $=$ other

English Speakers: Thanking $>$ Repayment $=$ Alerter $>$ Appreciate=positive feeling $>$ Apology $>$ Imposition $>$ other

Since thanking was the most frequently used strategy, its subcategories were studied in the following section in details. Looking into the subcategories of thanking strategy, Table 2 illustrated that $78 \%$ of the thanking strategies used by Persian EFL learners belonged to simple thanking. A number of examples from this group are thanks, thank you, thank you so much, many thanks. Similarly, Chinese EFL learners used $74 \%$ simple thanking strategy, whereas English native speakers tend to employ simple thanks less than the other two groups $(p=48 \%)$. Studying the groups in their use of the second sub strategy, thanking and mentioning favor, it seems that English speakers make use of this sub strategy more than Persian and Chinese speakers $(p=33 \%)$. It is apparent that English native speakers in comparison to both Persian and Chinese foreign language learners tend to use the third subcategory of thanking, expressing thanks, favor, and imposition more often $(\mathrm{p}=19 \%)$.

The summary of the results obtained is shown below:

Persian EFL learners: Simple thanking $>$ Thanking+favor $>$ Thanking+favor+imposition

Chinese EFL learners: Simple thanking $>$ Thanking + favor $>$ Thanking + favor+imposition

English Speakers: Simple thanking $>$ Thanking+favor $>$ Thanking+favor+imposition

\section{Discussion}

The present study attempts to provide some insight into the realization of speech act of gratitude by Chinese, Persian EFL learners and English native speakers in order to help EFL learners become familiar with rules and patterns dominating the speech act of gratitude in target language to communicate appropriately. The findings are in line with the belief that every language has the same set of strategies available for performing a given illocutionary act, but the preference of choosing strategies is culture-specific (Scollon and Scollon, 1995). The difference between all groups is identifiable in both level order and frequency of semantic formulas. It seems in some cases that the realization of this speech act and the way they are verbalized is different across cultures.

Considering the first goal of the study, the common patterns Persian EFL learners showed in their use of gratitude strategies is identified. Thanking strategy is the most preferred strategy in different situations. It seems that in most cases it is the most convenient way of showing gratitude, and also it became customary to use thanking strategy in addition to others. The second frequently used strategy was positive feeling since it might save the positive face of the 
speaker in communication while expressing gratitude. Hosseinimanesh (2011) stated that it may be because of the negative impact of their first language rules of speaking. Repayment and alerter strategies were used; because they help the interlocutors reveal their gratitude towards each other showing respect. Apology, appreciate, and other strategies were used equally in order to express their regard for the difference in social status and maintaining the conversation.

For the Chinese EFL learners, thanking, alerter, repayment and positive feeling were used more often. Apology, appreciation, imposition, and other were the strategies employed less by Chinese EFL learners. Chinese culture structure and values may be the cause of preferring different strategies. They tend to consider social status as the most important factor in using various strategies in expressing gratitude. As the social status becomes higher, their expressions of gratitude are more and lengthier. The reason why they have chosen thanking strategies as the more salient ones may be the fact that these strategies are the basic strategies which share the universal characteristics.

Discussing the third aim concerning specifying the pattern of gratitude expressions, it is inferred that English native speakers use thanking frequently in their interactions as their preferred approach in expressing gratitude. Repayment and alerter were equally common among English native speakers. Appreciation and positive feelings were also used by English native speakers; however, their frequency was less than the other strategies. Finally, imposition, apology and other were the least frequent strategies among English native speakers. The reason may be that they are grown up in a community that see people equal, and that's why they use thanking strategy more frequently in their daily interactions even for small favor, such as in bus and cashier situations (Cheng, 2005). Comparing the results of Chinese and English speakers, it is found that both groups generate similar strategies expressing their gratitude; therefore, the findings of the study are consistent with Cheng's findings (2005) and Chang (2008) that there is no significant difference in use of strategies.

Regarding the fourth goal of the study, the findings indicated that thanking is regarded as the favorite strategy among all three groups. Chinese EFL learners used thanking strategy more than Persian EFL learners and English native speakers. As stated by Bardovi-Harling and Rose and Nickels (2008) EFL learners acquire the frequently used strategy sooner, thanking is used as the essential strategy among participants, it may be concluded that cultures are similar in employing this strategy. The way each concept is realized in one culture differs from what it is in another, as the results of the study revealed there were some formulaic expressions among Persian speakers that could not be mutually translated. For instance, Persian learners made use of semantic formulas that showed the strong ties they have with their religion like 'May God bless you 'and 'God willing I promise to do my best to return your money' in the situation that native speakers of English may use repayment strategy. Instances like 'your eyes see beautifully' in order to agree and show their responses to hearer also were regularly used by Persian speakers. There are significant differences in the ways Persian learners of English and native speakers of English use the speech act of thanking due to the differences in their cultural backgrounds. Persian EFL learners employed positive feeling strategy more than the other two, it might be due to maintaining their own face. Therefore, in order to be polite, Persian speakers translated their cultural semantic formulas inappropriately in interactions. As a result, because of this negative transfer, native speakers misunderstand the expressions. In both English and Chinese, differences are evident in what to thank for and whom to thank. English speakers see everyone equal, and as a result they would express their gratitude in every situation they get help, offer and service, while the Chinese people tend to thank those who mainly help them many times (Wang, 2011).

Cross-cultural misinterpretation can lead to annoyance or even serious offense. Pragmatic awareness can ease the process of familiarizing with the conventions of L2 language. By focusing on teaching pragmatic usage of the language, EFL instruction enables learners to understand authentic English usage and moreover, give them the opportunity to comprehend native speaker's pragmatic intentions (Hwang, 2008). It is important to consider the fact that intercultural differences are not only related to words, grammar, and pronunciations but also to the ways of using language. Cultural differences in using languages are usually ignored. Teacher should let students make pragmatic decisions to break the rules if they wish to understand the differences between pragmalinguistics and sociopragmtics failures. Learners should be given the opportunity of choosing to be polite or impolite (Thomas, 1983).

More studies are needed to investigate learners' perception and production of gratitude expression in different cultures considering politeness. Also a similar study can be done with another format of data collection, adding to the results of the current study. Also, it is worth investigating the effect teaching speech acts in classrooms has on the perception of learners.

\section{References}

Amaya, L. F. (2008). Teaching culture: Is it possible to avoid pragmatic failure? Revista Alicantina de Estudios Ingleses, 21, 11-24 
Apte, M. L. (1974). "Thank you" and South Asia languages: A comparative sociolinguistic study. Linguistics, 136, 67-89

Austin, J. L. (1962). How to do things with words. Cambridge, MA: Harvard University Press.

Brown, J. D. (2001). Pragmatics tests: Different purposes, different tests. In K. R. Rose, \& G. Kasper (Eds.), Pragmatics in language teaching. New York: Cambridge University Press.

Brown, P., \& Levinson, S. D. (1987). Politeness: Some universals in language usage. Cambridge: Cambridge University Press.

Bardovi-Harlig, K. (2001). Evaluating the empirical evidence: Grounds for instruction in $\quad$ Pragmatics. In K. R. Rose, \& G. Kasper (Eds.), Pragmatics in language teaching. New York: Cambridge University Press.

Bardovi-Harlig, K., \& Dörnyei, Z. (1998). Do language learners recognize pragmatic violations? Pragmatic vs. grammatical awareness in instructed L2 learning. TESOL Quarterly, 32, 233-262

Bardovi-Harling, K., Rose, M., \& Nickels, E. L. (2008). The use of conventional expressions of thanking, apologizing, and refusing. In proceeding of the 2007second language research forum, Cascadilla Proceedings Project, Somerville, MA. pp. 113-130

Blum-Kulka, S. (1982). Learning how to say what you mean in a second language: A study of the speech act performance of learners of Hebrew as a second language. Applied Linguistics, 3, 29-59. http://dx.doi.org/10.1093/applin/III.1.29

Blum-Kulka, S., \& Olshtain, E. (1986). Too many words: Length of utterance and pragmatic failure. Studies in Second Language Acquisition, 8(2), 165-179. http://dx.doi.org/10.1017/S0272263100006069

Clankie, S. M. (1993). The use of expressions of gratitude in English by Japanese and American university students. Journal of inquiry and research, 58, 37-71

Cohen, A. D. (1996). Speech acts. In McKay, S. L., \& Hornberger, H. N. (Eds.). Sociolinguistics and language teaching. Cambridge: Cambridge University Press. (Chapter 12)

Creese, A. (1991). Speech act variation in British and American English. Penn Working Papers in Educational Linguistics, 7(2), 37-58

Eisenstein, M., \& Bodman, J. W. (1986). "I very appreciate": Expressions of gratitude by native and nonnative speakers of American English. Applied Linguistics, 7, 167-185. http://dx.doi.org/10.1093/applin/7.2.167

Eisenstein, M., \& Bodman, J. W. (1993). Expressing gratitude in American English. In G. $\quad$ Kasper $\quad \& \quad$ S. Blum-Kulka (Eds.), Interlanguage pragmatics. New York: Oxford University Press. pp. 64-81

Farnia, M., \& Suleiman, R. (2009). An Interlanguage Pragmatic Study of Expressions of Gratitude by Iranian EFL Learners - A Pilot Study. Malaysian Journal of ELT Research, 5, 108-140

Ghobadi, A., \& Fahim, M. (2009). The effect of explicit teaching of English 'thanking formulas' on Iranian EFL intermediate level students at English language institutes. System, 37, 526-537. http://dx.doi.org/10.1016/j.system.2009.02.010

Hosseinimanesh, L. (2011). Cultural differences between English and Persian in technical translation. International Journal of English Linguistics, 1(1), 227-235

Hwang, C. C. (2008). Pragmatic conventions and intercultural competence. The linguistics journal, 3(2), 31-48

Intachakra, S. (2004). Contrastive pragmatics and language teaching: apologies and thanks in English and Thai. RELC, 35(1), 37-62. http://dx.doi.org/10.1177/003368820403500105

Jung, W. H. (1994). Speech acts of "Thank You" and responses to it in American English. Paper presented at the Annual Meeting of the American Association for Applied Linguistics. Baltimore: U.S.A.

Kasper, G., \& Rose, K. R. (2002). Pragmatic development in a second language. Michigan: Blackwell.

Koike, D. A. (1989). Pragmatic competence and adult L2 acquisition: Speech acts in interlanguage. The Modern Language Journal, 73, 279-289

Lee, C. (2005). A cross-linguistic study on the linguistic expressions of Cantonese and English requests. Pragmatics, 15(4), 395-422

Matsuda, M. (1999). Interlanguage pragmatics: What can it offer to language teachers? The CATESOL Journal, 11(1), $39-59$ 
Olshtain, E., \& Cohen, A. D. (1991). Teaching speech behavior to nonnative speakers. In M. Celce-Murcia (ed.), Teaching English as a second or foreign language. Boston: Heinle and Heinle Publishers. pp. 154-169

Robin, J. (1983). How to tell when someone is saying 'no'revisted. In Wolfson, N. \& Judd, E. (Eds), Sociolinguistic and language acquisition. Rowley, MA: Newbury House.

Rose, K., \& Kasper, G. (2001). Pragmatics and language teaching. Cambridge: Cambridge University Press.

Scollon, R., \& Scollon, S. (1995). Intercultural communication. Oxford: Blackwell.

Searle, J. (1976). The classification of illocutionary acts. Language in Society, 5(1), 1-24. http://dx.doi.org/10.1017/S0047404500006837

Thomas, J. (1983). Cross-cultural pragmatic failure. Applied Linguistics, 4, 91-112. http://dx.doi.org/10.1093/applin/4.2.91

Tian, J. (2010). A comparative study of Chinese and American cultural context and the influence on communication. Journal of Language Teaching and Research, 1(4), 524-526. http://dx.doi.org/10.4304/j1tr.1.4.524-526

Wang, J. (2011). Cultural differences and English teaching. English Language Teaching, 4(2), 223-230. http://dx.doi.org/10.5539/elt.v4n2p223

Wolfson, N. (1981). Compliments in cross-cultural perspective. TESOL Quarterly, 15(2), 117-24

Table 1. Frequency and Percentage of Gratitude Strategies

\begin{tabular}{|c|c|c|c|c|c|c|}
\hline \multirow{2}{*}{} & \multicolumn{2}{|l|}{ Persian EFL learners } & Chinese EFL learners & \multicolumn{2}{l|}{ English Speakers } \\
\cline { 2 - 7 } & Frequency & Percentage & Frequency & Percentage & Frequency & Percentage \\
\hline Thanking & 1437 & $43 \%$ & 373 & $48 \%$ & 274 & $35 \%$ \\
\hline Appreciate & 90 & $3 \%$ & 40 & $5 \%$ & 94 & $12 \%$ \\
\hline Positive feeling & 752 & $23 \%$ & 90 & $11 \%$ & 96 & $12 \%$ \\
\hline Repayment & 413 & $12 \%$ & 95 & $12 \%$ & 103 & $13 \%$ \\
\hline Apology & 110 & $3 \%$ & 52 & $7 \%$ & 52 & $7 \%$ \\
\hline Imposition & 36 & $1 \%$ & 17 & $2 \%$ & 46 & $6 \%$ \\
\hline Alerter & 401 & $12 \%$ & 102 & $13 \%$ & 106 & $13 \%$ \\
\hline Other & 93 & $3 \%$ & 15 & $2 \%$ & 21 & $2 \%$ \\
\hline Total & 3332 & $100 \%$ & 784 & $100 \%$ & 792 & $100 \%$ \\
\hline
\end{tabular}

Table 2. Frequency of Subcategories of Thanking Strategy

\begin{tabular}{|c|c|c|c|c|c|c|}
\hline & \multicolumn{2}{|c|}{ Simple thanking } & \multicolumn{2}{c|}{ Thanking+favor } & \multicolumn{2}{c|}{ Thanking+favor+imposition } \\
\hline Persian EFL & 1117 & $78 \%$ & 305 & $21 \%$ & 15 & $1 \%$ \\
\hline Chinese EFL & 275 & $74 \%$ & 93 & $25 \%$ & 5 & $1 \%$ \\
\hline English speakers & 131 & $48 \%$ & 92 & $33 \%$ & 51 & $19 \%$ \\
\hline
\end{tabular}

\section{Appendix}

Dear participant,

Thank you for participating in this survey. This study is intended to explore cross cultural and Interlanguage speech behavior. The information you provide below will be used for this study only and will remain confidential. In the 
following section, please mark an ' $\mathrm{X}$ ' between the boxes corresponding to your response.

\section{Background information:}

Name:

Intended/completed Degree: BA

Year: FreshmanO

Age:

Gender: Male

\section{Instruction}

You will find the following scenarios involve being placed in a situation where you may feel, to different degrees, obliged or grateful to someone who has done something for or requested of/from you. Please imagine yourself in each situation and respond accordingly based on your immediate reaction. If you feel that a specified situation does not warrant a response, please provide an explanation.

1. It is Friday. You look into your wallet and notice that you only have $\$ 2.00$. your good friend at work notices this and hears you say,' I'll have to go to the bank.' Your friend asks if you need money, and you say that you forgot to go to the bank. Your friend says, 'I have plenty. How much do you need?' You say, 'Could you lend me \$5.00? I'll pay you back on Monday.' Your friend says, 'Sure. Are you sure you don't need more than that?' You say you don't. Your friend gives you the $\$ 5.00$.

\section{You would say:}

\section{You would say nothing because:}

2. You board the bus, pay your money and take a seat near the front of the bus. Just before your stop, you guess that the driver is not going to stop. You move to the front, and ask the driver to stop and he stops.

You would say:

You would say nothing because:

3. It is your birthday, and you're having a few people over for dinner. A friend brings you a present. You unwrap it and find a blue sweater that you wish to have.

\section{You would say:}

\section{You would say nothing because:}

4. You work for a large company, which is usually very busy. You send your manager a request for some days off. The vice-president of personnel calls you into his office. He tells you to sit down. You feel a little nervous, because you have only been working there for six months. The vice-president says, You're doing a good job. In fact, we are so pleased with you that I am going to give you a raise'.

\section{You would say:}

\section{You would say nothing because:}

5. In the supermarket, you ask the cashier to bag your groceries. He does this, and then turns to begin serving the next costumer. You pay and pick up your bags to leave.

\section{You would say:}

You would say nothing because:

6. At the table in a restaurant a friend says, you have something on your face.' You ask where. Your friend tells you. You rub your face and ask,' Is it off?' your friend says that it is.

\section{You would say:}

\section{You would say nothing because:}

7. You find yourself in sudden need of money-- $\$ 500$. You mention this to a friend. Your friend immediately offers to lend it you. At first you say, 'Oh no, I didn't mean it as a request. I couldn't take it.' Your friend says,' Really, it's all right. What are friends for?' Your friend insists again, and you take the check.

\section{You would say:}

You would say nothing because: 
8. You are studying in another city. Both you and your roommate work. You come home late from work and find that your roommate has done some work around the house that you had promised to do, but had not had a chance to do.

You would say:

You would say nothing because:

9. Your friend suggests going out to lunch. You say that you'd like to go, but you only have $\$ 2$. Your friend says. 'Ah, don't worry. I'll treat you today.' Your friend takes you to a very nice restaurant -a much more expensive one than you usually go to. You have a wonderful meal. Your friend pays, and you get up to leave.

\section{You would say:}

You would say nothing because:

10. You have just gotten an admission from a foreign university. A close friend in the university tells you she has organized a farewell party for you.

You would say:

You would say nothing because:

11. You have just gotten your hair cut in a new style, and you like it better than the old one. Your friend sees it and you ask him what he thinks. He says, 'Hey, you've got a new haircut. It looks nice.'

\section{You would say:}

\section{You would say nothing because:}

12. You share an apartment with a friend. You're both sitting and relaxing in the living room. You ask your friend to hand you the newspaper which is nearby. Your friend gives you the newspaper.

You would say: Thanks.

You would say nothing because:

13. You enter a parking garage. As the parking attendant gives you the parking voucher, You hand him the money and ask him about the empty space.

\section{You would say:}

\section{You would say nothing because:}

14. You have been invited to the home of a rather new friend. You have dinner with him and his family and a few other friends of theirs. The food was great, and you really enjoyed the evening. As you leave, your hosts accompany you to the door.

\section{You would say:}

You would say nothing because: 